\title{
Aortic atresia with "corrected transposition of the great arteries" (atrioventricular and ventriculoarterial discordance)
}

\author{
JOHN E DEANFIELD, ROBERT H ANDERSON`†, FERGUS J MACARTNEY†
}

From the Thoracic Unit, The Hospital for Sick Children, Great Ormond Street, London

SUMMARY Aortic atresia occurring with atrioventricular and ventriculoarterial discordance ("congenitally-corrected transposition") and an Ebstein-like anomaly of the left atrioventricular valve has not previously been reported. A patient with this condition is described, in whom the diagnosis was established in life by angiocardiography, and confirmed at necropsy.

Aortic atresia is usually a lethal condition, most commonly associated with an imperforate aortic valve and ventriculoarterial concordance, or else with complete absence of the aortic valve. ${ }^{1-3}$ This case is presented as an example of the rare association of aortic atresia with ventriculoarterial discordance.

\section{Case report}

A male Caucasian infant with a birthweight of $2.8 \mathrm{~kg}$ was born by normal delivery after a full-term pregnancy. No abnormality was detected at birth, with Apgar scores of 7 at one minute and 9 at five minutes. He was noted, however, to be cyanosed four hours later and was referred to The Hospital for Sick Children for further investigation. There was no family history of congenital heart disease.

On examination there was mild cyanosis at rest which increased conspicuously on crying. The arm and superficial temporal pulses were impalpable but the femoral pulses were normal. The heart rate was 150. per minute and regular. Auscultation disclosed an ejection systolic murmur at the left sternal border and a continuous murmur audible below the left clavicle. The second heart sound was single. The baby was tachypnoeic and the liver was felt $5 \mathrm{~cm}$ below the

\footnotetext{
- Present address: Cardiothoracic Institute, Brompton Hospital, Fulham Road, London.

† RHEA and FJM are supported by the British Heart Fonndation and, respectively, the Joseph Levy and Vandervell Foundations.
}

costal margin. The rest of the physical examination was normal.

\section{INVESTIGATIONS}

Cardiac chambers will be named according to morphology not position.

The chest radiograph and high kilovoltage filter beam radiograph of the bronchi ${ }^{4}$ disclosed situs solitus of the atria and viscera. The heart shadow was enlarged, with slightly increased pulmonary vascular markings. An electrocardiogram showed sinus rhythm with a mean front QRS axis of $+90^{\circ}$ and a clockwise frontal plane vector loop. The praecordial leads showed small q waves in leads V4R and V7, but not in between, a dominant $R$ wave in V4R, and a dominant $S$ wave in V1. These findings, together with an $18 \mathrm{~mm} R$ wave preceded by a $2 \mathrm{~mm}$ q wave in aVF, were interpreted as showing left ventricular hypertrophy.

The haemoglobin was $16 \mathrm{~g} / \mathrm{dl}$ and the femoral arterial $\mathrm{PO}_{2}$ in air was $37 \mathrm{mmHg}$. Cardiac catheterisation and angiocardiography were performed on the day of admission. The left atrial mean pressure was 4 mmHg whereas that in the right atrium was $1 \mathrm{mmHg}$. The pressure in the right ventricle (entered from the left atrium) was $40 / 0-8 \mathrm{mmHg}$ whereas the pressure in the left ventricle (entered from the right atrium) was 80/0-4 $\mathrm{mmHg}$. There was a $20 \mathrm{~mm}$ systolic pressure gradient between the left ventricle and pulmonary artery and further $20 \mathrm{~mm}$ gradient between the pulmonary artery and descending aorta, reached via a persistent ductus arteriosus. 
Angiocardiograms (Fig. 1) in the right ventricle, left ventricle, and pulmonary artery showed atrioventricular discordance. The systemic venous atrium communicated with a smooth-walled left ventricle which gave origin to the pulmonary artery. Pulmonary arteriography showed filling of the entire aorta through a persistent ductus arteriosus. The retrogradely filled aortic arch and ascending aorta were grossly hypoplastic, terminating in an aortic root containing an imperforate aortic valve anterior to the pulmonary valve.

Pulmonary venous return was to the left atrium. This connected to the small right ventricle anterior and to the left of the left ventricle. Selective right ventricular angiocardiography showed conspicuous displacement of the left (tricuspid) atrioventricular
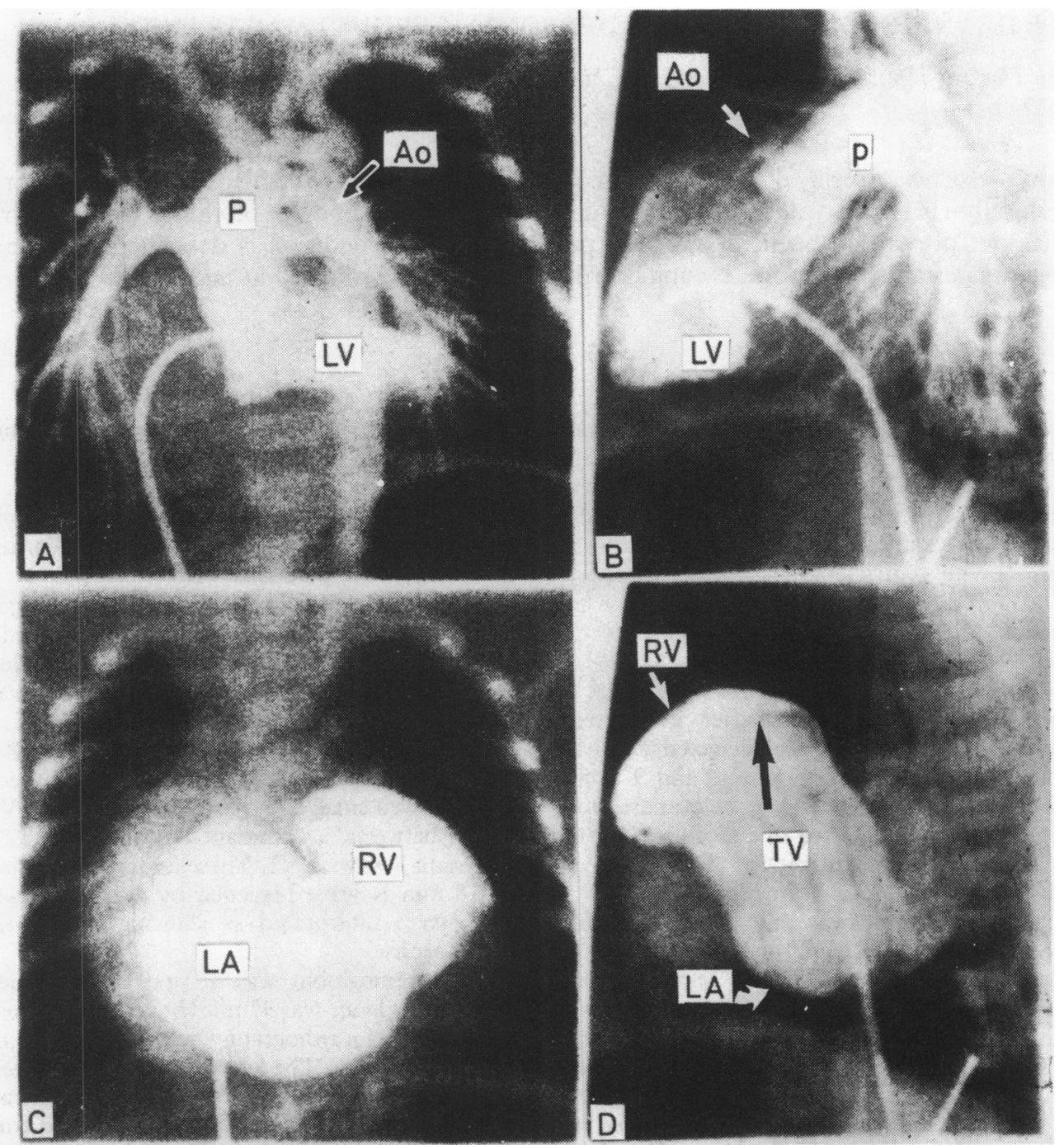

Fig. 1 (A) Frontal view of selective left ventricular angiocardiogram. The typcially smooth walled left ventricle (LV) empties into the pulmonary artery $(P)$, which supplies the aorta $(A o)$ via a persistent ductus arteriosus. $(B)$ Lateral projection, selective injection into the left ventricle. Abbreviations as in $(A)$. Note the retrograde filling of the thread-like ascending aorta, terminating with slight dilatation of the aortic sinuses. $(C)$ Frontal projection, selective injection into right ventricle $(R V)$. Note that the right ventricle lies to the left of and above the left ventricle, and there is severe regurgitation in the left atrium $(L A)$. (D) Lateral projection of selective injection into right ventricle. Abbreviations as in $(C)$. Note the gross displacement of the tricuspid annulus (TV) into the right ventricle, and the severe tricuspid regurgitation. 


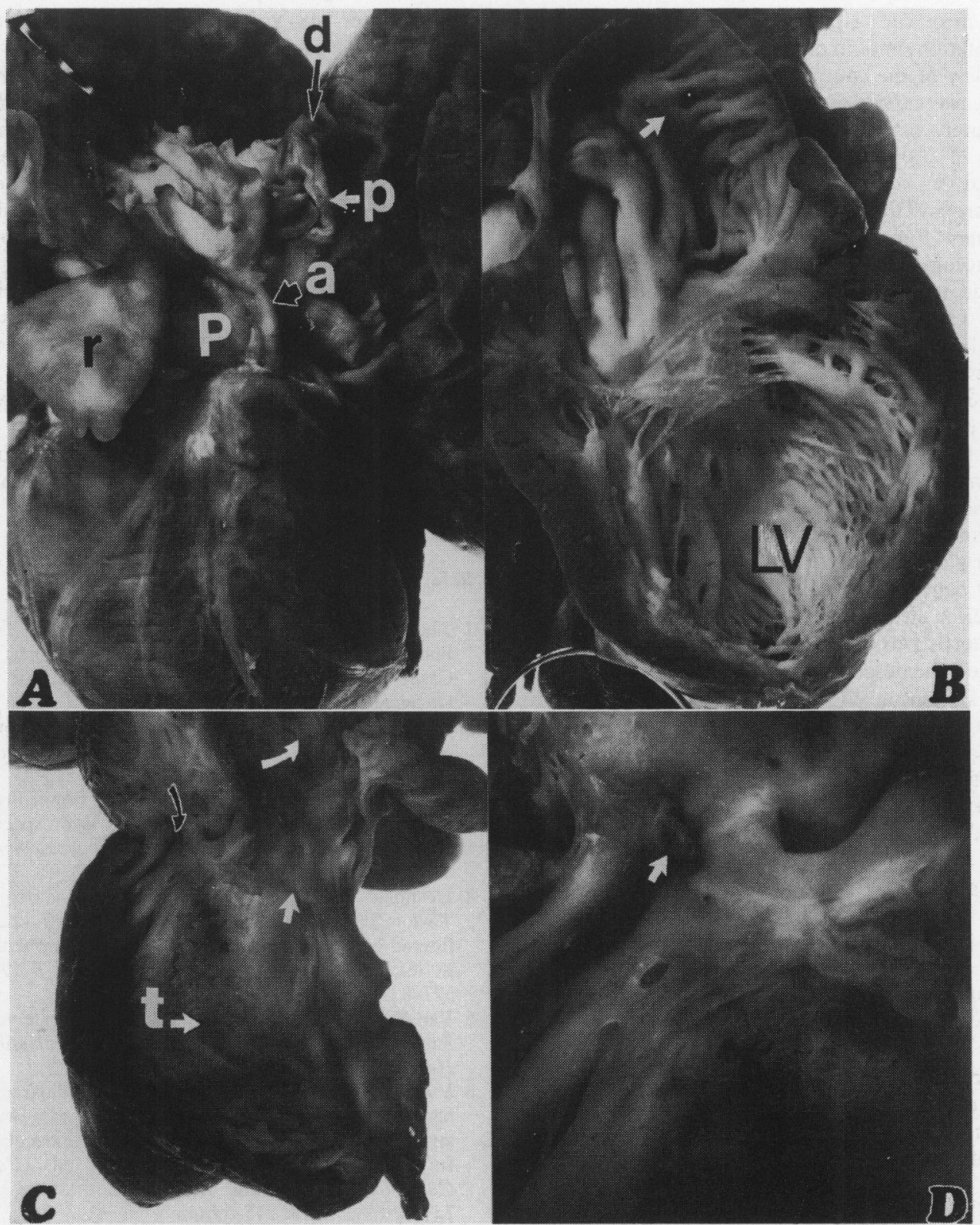

Fig. 2 (A) Frontal view of the exterior of the heart. Note the broad right atrial appendage ( $r$ ). The ascending aorta (a) lies anterior and to the left of the greatly dilated pulmonary trunk $(P)$. Through a persistent ductus arteriosus $(p)$, the aorta is supplied both in its ascending and descending $(d)$ portions. $(B)$ View of the right atrium and left ventricle $(L V)$. Note the typical morphological features of a right atrium, including the crista terminalis (white arrow). The left ventricle has a smooth septal surface and fine trabeculations, and between the right atrium and left ventricle is a morphologically mitral valve. The left ventricle gave origin to the pulmonary artery. (C) View of the left atrium and right ventricle. The free wall of the right ventricle has been retracted superiorly. Note the typical morphological appearances of the left atrium, including the flap valve of the foramen ovale (curved arrow). The true position of the tricuspid annulus is shown (straight white arrow). There is obviously gross displacement of the tricuspid valve (t) into the right ventricle, which is in fact much smaller than the left ventricle, but shows the typical course trabecular pattern of a morphologically right ventricle. The imperforate aortic valve is just seen (black arrow). (D) Magnified view of the aortic valve, orientated as in C. By placing a probe down the ascending aorta, the imperforate aortic valve has been inverted so that it protrudes into the right ventricle (white arrow). 
valve into the right ventricle, gross tricuspid regurgitation, and no other egress from that chamber.

In view of the complexity of the cardiac defect no surgery was carried out and the baby died at home one week later.

\section{NECROPSY}

At necropsy the angiocardiographic diagnosis was confirmed (Fig. 2). There was atrial situs solitus. The morphologically right atrium received normal systemic venous drainage and was connected via a mitral valve with a typical morphologically left ventricle. This chamber gave rise to a large posterior pulmonary trunk. The morphologically left atrium received four pulmonary veins and was dilated. There was a patent foramen ovale. The left atrium communicated with a morphologically right ventricle via an abnormal tricuspid valve. This had features reminiscent of Ebstein's malformation, with the septal and inferior leaflets plastered down to the wall of the right ventricle which was about half the size of the left ventricle. The outlet of the right ventricle to an anterior situated aorta was blocked by an imperforate aortic valve. The ascending aorta was extremely small and the descending portion was fed by a narrow ductus arteriosus. This showed signs of closure. Thus the pathological diagnosis was: (1) situs solitus discordant - discordant; (2) imperforate aortic valve; (3) aorta anterior and to the left; (4) malformation of the left atrioventricular valve (tricuspid) similar to Ebstein's anomaly.

\section{Discussion}

Aortic atresia may be associated with a variety of cardiac conditions, but it is very rarely found with ventriculoarterial discordance (transposition). We are aware of four such published cases. Two had univentricular hearts of left ventricular type, one with valvular and subvalvular aortic atresia ${ }^{5}$ and the other with functional subaortic atresia. ${ }^{6}$ A recent review of the latter specimen has shown that a tiny outlet foramen was blocked by left atrioventricular valve tissue. The third case had atrioventricular concordance. ${ }^{7}$ The fourth had atrioventricular discordance, but virtually no tricuspid valve. What tricuspid valve there was arose from the normal atrioventricular valve annulus. ${ }^{8}$ In that patient, unlike ours, the diagnosis was not established during life.

In the common form of aortic atresia with normal cardiac connections, the burden of the circulation falls on the right ventricle. The prognosis is very poor, with a mean survival of 13 days $^{7}$ and a longest reported survival of three and a half years. ${ }^{3}$ The patient alluded to above had aortic atresia with complete transposition of the great arteries ${ }^{7}$ and has survived for six years. To explain this increased longevity it was suggested that the morphologically left ventricle is better able to support the systemic and pulmonary circulation load than is the right ventricle (in aortic atresia with normal connections). At first sight, the patient here described disproves this hypothesis, since despite the fact that the left ventricle supported both pulmonary and systemic circulations, death occurred at 8 days of age. The systolic pressure gradient between the pulmonary artery and descending aorta present at cardiac catheterisation, however, suggests that the ductus arteriosus (upon which the systemic circulation depended) was already constricting on the first day of life so that this, rather than ventricular morphology, determined survival.

We are grateful to Dr R Carter, consultant pathologist of the Swindon Health District, for making available the necropsy specimen.

\section{References}

1 Thiene G, Gallucci V, Macartney FJ, Del Torso S, Pellegrino PA, Anderson RH. Anatomy of aortic atresia. Cases presenting with a ventricular septal defect. Circulation 1979; 59: 173-8.

2 Freedom RM. Aortic atresia. In: Keith JD, Rowe RD, Vlad P, eds. Heart Disease in Infancy and Childhood. New York: Macmillan, 1978: 542-8.

3 Moodie DS, Gallen WJ, Friedberg DZ. Congenital aortic atresia. Report of a long survival and some speculations about surgical approaches. $\mathcal{F}$ Thorac Cardiovasc Surg 1972; 63: 726-31.

4 Deanfield JE, Leanage R, Stroobant J, Chrispin AR, Taylor JFN, Macartney FJ. Use of high kilovoltage filtered beam radiographs for detection of bronchial situs in infants and young children. $B r$ Heart $\mathcal{F} 1980 ; 44$ : 577-83.

5 Van Praagh R, Plett JA, Van Praagh S. Single ventricle. Pathology, embryology, terminology and classification. Herz 1979; 4: 113-50.

6 Macartney FJ, Anderson RH. Angiocardiography and haemodynamics of the univentricular heart with two atrioventricular valves or a common atrioventricular valve. In: Anderson RH, Shinebourne EA, eds. Paediatric Cardiology 1977 Edinburgh \& London: Churchill Livingstone, 1978: 345-59.

7 McGarry KM, Taylor JFN, Macartney FJ. Aortic atresia occurring with complete transposition of great arteries. $\mathrm{Br}$ Heart F 1980; 40: 711-3.

8 Brenner JI, Bharati S, Winn WC Jr, Lev M. Absent tricuspid valve with aortic atresia in mixed levocardia (atria situs solitus, L-loop). A hitherto undescribed entity. Circulation 1978; 57: 836-40.

Requests for reprints to Professor F J Macartney, The Hospital for Sick Children, Great Ormond Street, London WCIN 3JH. 